STUDIA UBB PSYCHOL.-PAED., LXVI, 1, 2021, p. 91 - 110

(Recommended Citation)

DOI:10.24193/subbpsyped.2021.1.05

\title{
GROUP DEVELOPMENT STAGES. A BRIEF COMPARATIVE ANALYSIS OF VARIOUS MODELS
}

\author{
SEBASTIAN VAIDA ${ }^{1 *}$, DAN ȘERBAN ${ }^{1}$
}

\begin{abstract}
Group Development is one of the most important cornerstones of social life. It dictates how our work and social circles develop and influences the relationships in our lives, and in turn, these relationships dictate the levels of satisfaction we report in our lives. Teamwork is also important in our experiences as it is strongly related to group development and is linked with many aspects, such as professionalism and efficiency in teams. In this paper, we discuss the importance of group development for any forming teams and analyze the concept within nine models (Bass and Ryterband, Tubb, Cog's Ladder, Homan, Woodcock, Fisher, Jones, Tuckman and Wheelan), with a particular accent on the last two (Tuckman and Wheelan).
\end{abstract}

Keywords: groups, teams, development, model, work, stages.

\section{Introduction}

Teams have existed for as long as humanity has. From the huntergatherer communities who worked together to ensure their survival, to the medieval condottieri who traded their military prowess for coins, and the modern football players who entertained the masses with their coordinated ball-kicking tactics, they have been, are and will continue to be our greatest tool. Though we can greatly attribute our success to our ability to pool our resources together, our odds of surviving the modern socio-political, environmental and technology struggles of the 21st century require us to have a closer look at how we work together and how we take on the challenges as a group.

1 Faculty of Psychology and Educational Sciences, Babeş-Bolyai University, Cluj Napoca, Romania

* Corresponding author: sebastianvaida@psychology.ro 
However, we would not be the first to do so. In 1939, as the Second World War was raging in Europe, a German American named Kurt Lewin coined this concept in a Three Styles Model. Thus, highlighting a set of team leading philosophies generally used in all types of organizations, according to their focus. As a result, the Delegative, Authoritarian and Participative models were established. The Authoritarian style best fits high-risk situations that develop under a short time span and is marked by the order-like style of goal setting and method choosing of the leader. The Delegative style is the opposite of the former, centered around a laid-back perspective of work and allowing as much as possible self-governing ability to the team. The middle ground is met by the Participative model. However, all this only increasingly added stress on the literature and pointed out the lack of a proper model and analysis of how teams truly perceived work and their members.

One of the main authors of such an analysis has been Bruce Tuckman, who in 1965 has proposed his famous team-development model. The model highlighted four stages that all teams must go through, to function at their full capacity.

The first stage, Forming, is marked by a lack of role clarity and a desire of assessing the capacities and desires of fellow team-members. Within this stage, most teams assign a leader and form an opinion about the others and the tasks at hand.

The second stage, Storming, is characterized by an innate struggle for leadership roles, compromises, uncertainties, and a risk of dismantling through emotions and relational causes.

The third stage, Norming, is heavily marked by a movement towards progressing the task through establishment of rules, roles, and processes, it is usually the stage in which discontent drops and acceptance of the team's style prevails.

The fourth stage, Performing, is generally marked by peak efficiency and coordination within the team as most of the processes go smoothly and relationships between members flourish.

However, over the next decade, Tuckman added a fifth stage, Adjourning, which is crucial to our understanding of how the model is anticipating the separation of a group and processes that accompany it. As Natvig (2016, p 678) carefully observed, "During the adjourning stage, the group performs a selfevaluation and analysis and reviews the outcomes of the project. This stage may include separation anxiety and mourning as the project team disbands, as well as feelings of accomplishment that tasks were completed.". Therefore, it seems that in more recent years the concerns of the transitional periods and disbandment of teams, as well as their consequences have been the focus of researchers. 
In this analysis, we have looked at nine models that discuss and define the concept of group development stages, and we present them in the main body of the study, pointing out the characteristics, as well as the plusses and weaknesses.

\section{Tuckman's Team Stages}

\section{Stage One: Forming}

According to Bonebright (2010), the first prerequisite of a team is establishing a set of relationships between the team members. One must always keep in mind that there can be an infinite number of possibilities when concerning pre-existing relationships between team members. The implications of these pre-existing conditions may or may not greatly affect the experience of the first stage of development.

The first stage is essentially the process of assembling an initial structure for the team. For the average person this is marked by an elevated degree of ambiguity and as our innate instincts dictate that we must be accepted by the new group, by an extensive effort to avoid conflict-generating situations. According to Tuckman's works $(1965 ; 1977)$, behaviors exhibited by individuals can be politeness, assessment of peers' personality and aligning to them, discussions of problems unrelated to the scope of the team and an attempt to define processes and tasks. The general feelings can be marked down as optimism, anticipation, suspicion, fearfulness, and anxiety related to teamwork. Personal relations are marked by dependency and group members follow safe behavior patterns. In this stage, the preferences for the future subgroups are formed and serious topics and feelings are avoided.

Considering the needs that the team requires, we can identify a need for a team vision, an establishment of ground rules and a role assignment. Therefore, a leader can be expected to give the team structure, guidance, create an atmosphere of acceptance, actively involved in the processes associated with meeting each other and offer the team some breathing room and time for getting acquainted. For the team to advance to the next stage, it is required of it to experience these situations.

\section{Stage Two: Storming}

According to Seck (2014), conflict is an inherent part of team progression and inevitable in the normal development of a team. It cannot be avoided if we expect a team to reach its full potential, as it warrants the strengthening of a 
team's processes. Seck (2014) further explains how this stage is the time for the stating opinions, concerns, and suggestions. On top of this, the stage seems to exist for the accommodation and acclimatization of those frustrated with the current stratagems. Seck (2014) underlines the importance of communication in this stage, as without it the team can only grow frustrated and may be at risk of not resolving important conflicts. Personal relations in this stage are characterized by competitiveness and conflicts, which inevitably appear when members try to focus on tasks.

Tuckman (1965) himself notes how this stage is dominated by a power struggle and a necessity to question the leadership and structure of a team. Among observable behaviors, we can note arguments, a lack of role clarity and generally lack task progress. Jones (2019) notes how this stage is noteworthy for the incentive properties it has, as team members are challenged to engage further in complex intellectual processes. As the group becomes more and more hostile to itself, it expresses its members' individuality and as a result, Jones (2019) explains how strong emotions may arise during this stage.

Ito \& Brotheridge (2008) note that this stage may occur several times during a project, as team members will grow comfortable with one another over time and may desire to make their opinions known later.

What is certain is that, according to Tuckman (1965), at the end of this stage, the team is supposed to have already experienced a series of conflicts from which to discern: a revision of past norms and hierarchies, an inclination towards listening and offering feedback to your fellow team members and a further development of inter and intra-relationships. The leaders are expected to provide the strategies required to move on from unproductive conflict and ease in the feedback processes.

To be able to advance to a next stage, the team members must change their mindset from a "test and check" to a problem solving one and one of the most important features in this stage is the ability to communicate and listen.

\section{Stage Three: Norming}

As teams weather the storms of the previous stage and settle in for a more balanced state, it becomes clear that they are required to establish a guideline and focus on working together rather than struggling for power or arguing (Pugalis \& Bentley, 2013).

According to Tuckman, norming is the stage in which we can observe a transition from a singular leadership to a more open and shared style. Trust is essential to an effective leadership and thus it is a requirement for the team at this stage to avoid devolution. Bonebright (2010) specifically underlines the nature of the transition in the mindset of team members from the perspective 
GROUP DEVELOPMENT STAGES. A BRIEF COMPARATIVE ANALYSIS OF VARIOUS MODELS

of single work to one of assimilation to the group as a bigger entity. Thus, as members are crafting an in-group affiliation, they obtain a type of loyalty to the group and encourage the maintenance and improvement of the group itself.

Furthermore, it is notable that the degree of freedom of speech is soaring during this stage. Therefore, it is expected that the group establishes a set of guidelines and focus on establishing the protocols, plans and seek perfecting the performance-related processes. An important part of this stage is also the encouragement of creativity and harmony. Wheelan (1996) adds that behaviors encouraging structure and discovery of roles within the limits of helpfulness are accepted. Gren, Torkar \& Feldt (2017) goes even further and explains that the third stage is the backbone for the competence-related abilities of the group. The leader takes a more consultative approach to the process, in a bid to increase flexibility and allow the group to form its own directives. A degree of labor division adjusted to maximize productivity is also noted. Conflicts are still present, but greatly reduced in the degree of damage through more effective management than in the second stage.

Sometimes, there is the fear that the group might dissolve; therefore, there is a moderate resistance to any change.

\section{Stage Four: Performing}

This is the stage where most of the task work itself is accomplished. Gren, Torkar \& Feldt (2017) maintains that this is one of the longest stages and marks the fulfilment of the group's transition into a team in all its merit. As the focus moves to the bulk of the work itself, team cohesion is maintained diligently, and observers can note a degree of excitement in the team's work. Norms established in the prior stage are used to provide motivational support and high performance. Also, this is a stage that not all teams will reach, which explains why some teams will never have the expected results.

Seck (2014) notes that there are still conflicts, but the management is so effective at this stage that negotiation and communication disarm the destructive potential. In fact, Seck suggests that the relationships that have formed by this stage between members have a positive impact on both conflict management and the overall performance of the team. The work of an author named Brown (1991) is brought into the conversation and according to their paper, this stage can be condensed in two words: intimacy and maturity. Zhen (2017) notes that there is a beneficial cultivation of self-management and discipline at this stage.

However, Ito \& Brotheridge (2008) once again points out that there is a risk of deterioration at this stage, too. This deterioration (which can appear through a crisis type of event) can in fact, be used as a crutch to boost the team into a positive state rather than lead to the dissolution of the group. 


\section{Stage Five: Adjourning}

As mentioned above, Tuckman let the international literature filter his work and after over a decade of papers decided to add a stage that concerned the dissolution of a team. Also called the "termination" stage, adjourning the stage in which the team has fulfilled its purpose and must move on from its current formula due to a variety of reasons. Tuckman's 1977 model suggests that while the group continues to perform, the task itself is no longer the focus of the team. Instead, there is a cycle of emotions that must be handled. These emotions can be strong, and expressions include, but are not limited to crying, termination of interpersonal relationships, denial, and an overall feeling of sadness. This set of behaviors is why Jones (2019) mentions that this stage can itself be surmised as "mourning". Additionally, he mentions that while in environments where education is the product, we rarely see this development; it is widely used in organizational environments due to its re-organizational capabilities.

At this stage, the team members have developed and accomplished their task together and now celebrate their success. Jones (2019) continues to remark how there is an ambiguity and uncertainty shadowing this celebration, as a transition towards the unknown is possible. He recommends leaders to prepare a transitional plan to soften this stage and reduce the negative feelings associated with separation.

Notable for this stage is that it is not a terminus point for the entire group, and some veterans from the old team will carry on towards the next project and assist the formation of a new team with their accumulated experience. A self-analysis occurs at this point, so that the team can better understand their experiences. Several stages may even coexist at the same time during this step. It is also worth considering that this stage can facilitate a leap forward, over the usual timespan of the stages themselves (Zhen, 2017). A proper plan for this stage will include acknowledging all team members' involvement, as well as their achievements and the change to say goodbye and get a closure.

\section{Limitations and strengths of Tuckman's Work}

A simple Google Scholar search revealed that Tuckman's 1965 paper has been cited a remarkable 8766 times, while his later 1977 paper has been cited 3722 times, proving that it has held up well to the test of time, especially when compared to Bonebright's 2010 similar report. Given the high number of citations that has occurred over the decade (over 8000 combined citations), one can consider Tuckman's work has stood the test of time and remains relevant to the modern literature. 
However, Bonebright (2010) has underlined several limitations of both papers. First and foremost, Tuckman himself acknowledged a lack of representation for non-therapeutic environments due to his specialization as a psychologist. Furthermore, Bonebright (2010) noted that Tuckman's work has been generalized well beyond its original framework and highlighted the work of Cassidy (2007), who extensively described the lack of clarity in the second stage's definition in non-therapeutic groups. Bonebright (2010) continued to express concern regarding the methodology of the studies that treated the subject of the model, which were doubled by Tuckman's own 1977 paper. There have also been some questions raised by the rigidity of the model itself, as the stages may be more flexible than iterated in the model and deeply dependent to the precise size of the group (Sundstrom, De Meuse \& Futrell, 1990)

\section{Bass and Ryterband's Model}

A model proposed in 1979, Bass and Ryterband's focuses much more on group formation and control rather than a graduality in the group's evolution from end to end. The model is resource-centric and takes an extra step compared to other literature examples to explain how they are used in various development stages.

\section{- The Stage of Acceptance}

The initial stage of this model is different from other equivalents mentioned in this article due to its positioning in the timeframe of group development. It is only occurring after the initial struggles are overcome and a sense of collaboration and acceptance sediments. Bass and Ryterband (1979) explain that it involves information distribution on both a task-related level and an informal level, carefully patched by interpersonal bonds and tests on jobrelated experiences and otherwise.

\section{- The Stage of Communication and Decisions Making}

Based on the strides and advances of the previous step, the group develops an open style of information sharing. This communication style is necessary for quality decision making and can be viewed as a mix of uncovering previously hidden attitudes and opinions related to work tasks, as well as an evaluation of the processes and goals of the group.

- The Stage of Group Solidarity

After the group invests more resources and commitment into the project ensuring cooperation without underlying frustrations is achieved, the overall performance of the group skyrockets. This process is characterized by 
the advances the group undergoes and the heightened prosperity of the project. Compared to equivalents in literature, this stage is like Tuckman's stage of Performing.

- The Stage of Group Control

A stage that takes a dimension fairly ignored by other models, Group Control is characterized by the equity of work and maximization of support within the group. The members have developed enough that it is no longer required to keep a formal relation and cooperation even with tasks not attributed to individuals is noted (Zoltan \& Vancea, 2016; Bass and Ryterband, 1979).

\section{Tubb's Model}

A model proposed in 1978 and subsequently improved in later years, Tubbs' model, separates group evolution in four linear stages. The model treats group development from a systemic perspective, treating it much more like a process containing subprocesses than a straight developmental line for the group. Thus, it offers an organic dimension, explaining how these processes form the inputs, the outputs and the throughputs that can be extracted from the experiences that people who form teams undergo. As one can assume, the model (as explained by a synthesis in Tubbs' book detailing it) includes three elements that interact with one another: relevant background factors, internal influences, and consequences. This approach ensures that the group is not frozen in the rigidity of procedures set in stone, but that it can learn from the various hurdles it may encounter and integrate feedback into its course of action.

There are four stages within Tubbs' System Model:

- Orientation

During Orientation, the group members interact with each other and try to grasp an emerging strategy as set expectations about the work at hand. This stage is highly like other established models' initial steps, proposing that team members are looking for diplomatic solutions to any conflict from within. As the group gets to form connections and members start conjuring opinions on one another, a snapshot forms of how the group will operate and the initial anxieties and uncomfortable lack of social safety dissipate.

\section{- Conflicts}

During Conflict, the group is comfortable enough in its internal relationships and start focusing much more on the tasks rather than the social aspects of the team. As individuals are committing more and more to the project, they are about to 
reach a level of individuality that creates friction and conflicts. Tubbs ascertains that conflict is central to human interaction, therefore they are necessary to answer important questions within the group: who is the leader? what responsibilities belong to whom? does the established structure of the group function effectively? etc. It appears that during this phase the dominant members will inevitably go out of the safety of their positions and explore more and more opportunities, while the subservient ones will opt for a more silent approach.

- Consensus

Consensus is the stage that occurs when Conflict ends and presumes that the members understand their roles much better than priorly. During this stage, Tubbs noted a fluid interactive model, with far less friction during team processes and a heightened productivity. The input of each group member is valued and the inner working of problem-solving are based less on strife and desire to ascertain dominance and much more on finding impactful solutions through the best strategies that the group can conjure. While frictions may occasionally occur, they will not impact the group or the end products as heavily as the prior stage would suggest. Members will develop on an individual scale, as well on a group scale. Leadership can and will be passed in a distributed manner.

- Closure

During closure, the group has already completed their objective and are assessing the efficiency of processes they have undergone. A post-action phase, this includes the departure to other projects and teams, which other models would consider a different stage entirely. (Tubbs, 2012)

\section{Cog's Ladder}

A model that came about in 1972, Cog's Ladder of Group Development is a five-stage group development linear model. George Charrier concluded that there is an orientative "ladder" that all groups naturally follow with or without direct leadership. At the end of this model lays a highly productive stage, with low waste of resources and high performance. One should approach this model with similar expectations as Tuckman's model due to many common points.

\section{- $\quad$ The Polite Phase}

This phase is highly like other models' initial stages and surmises that members will avoid having behaviors that are not socially acceptable while also trying to assess their teammates. In a bid for approval, they will attempt to complete a jigsaw of interpersonal connections rather than focus on the task at hand. 
- “Why are we here?" Stage

Following the completion of acquaintances, a group desire to discuss the general objective of the team forms. Thus, the members start delegating tasks and much like the rest of literature seems to suggest, cliques of common goals, abilities and motivations will form. Performance starts improving and communication becomes smoother.

\section{- $\quad$ The Power Phase}

During the third stage, it becomes abundantly clear if there are any internal struggles as a social hierarchy develops and individuals will be inclined to claim various roles, creating conflict. As strife becomes the main occupation of the group, very rarely can we obtain results from this stage with power plays in the background. Even with moderators or incipient leaders assisting the stage, Charrier makes it very clear that until the internal politics are taking a more permanent form it should not be expected for the group to perform.

\section{- The Cooperation Phase}

The fourth stage begins immediately after a social hierarchy is defined and the struggles associated with political activity wind down. As leaders take their roles seriously, the author emphasizes the need for a team-wide contribution to decisions and warns against displacing the careful and brittle balance with new members.

\section{- The Esprit de Corps Phase}

"Esprit de Corps" comes from a military term which points out when a group exudes cohesion and inspires the members to be proud of their belonging to a group. Like the original expression, the fifth stage describes a team that has established its base and built on top of it, creating a safe environment for experimentation and productivity. The most important aspect, communication is at its peak and the main concern the group has is maintaining this high-level stage (Charrier, 1972).

\section{Homan's Model}

One of the oldest models covered in this paper is proposed by George Homans (part of the group that identified the Hawthorne effect) in 1950. The proposed model is a dissection of groups in two overarching systems: the external system and the internal system. The author makes a significant author in identifying the complex contexts in which groups can be found - ranging from 
explaining the physical surroundings to the technologies they use and the overall state of the organization they are in. Thus, Homans covers three stages that groups undergo, all while keeping in mind a constant pressure of contextual factors. Furthermore, due to the age of the model the reader should also not forget that the perspective is different from our modern understanding of groups and the author describes groups as "set up" by a third party with its own agenda and desired behaviors, rather than an organic process with high organizational flexibility as it is the case in contemporary organizations.

- The first stage concerns needed states and behaviors - actions and activities, interactions, needed norms and emotional experiences that are sought out for the group.

- The second stage concerns emergent states and behaviors - emergent actions, interactions, norms, and emotional experiences that result from the group interacting in time.

- The third stage concerns the results of collective actions - productivity, group members' satisfaction and personal development and evolution.

According to some authors (Curseu, 2007), there is a continuous interactivity and cross-influence between behaviors, states and conditions which come to influence the group and their effectiveness.

\section{Woodcock's Model}

Woodcock's 1979 model is a four-stage group development project. It is highly like Tuckman's own proposition and thus there are many overlapping aspects within it.

- Infant team - this is the initial stage and is generally now that a team has an avoidance of direct conversation on difficult topics, an unclear objective, and a heavy reliance on team leadership.

- Exploratory team - the second stage addresses a more direct approach on issues and relies on active listening as well as group introspectiveness for short periods.

- Under Consolidation team - this stage addresses a developing team and its communication and task clarification needs. During this stage, objectives and procedures are experimented with.

- Mature team - the stage is defined by the informal style of communication and open information transmission. Many alternative plans are considered, and a great degree of flexibility is indulged, as well as a clearer leadership style with a greater degree of responsibility taken (Zoltan \& Vancea, 2016; Woodcock, 1979). 
SEBASTIAN VAIDA, DAN ȘERBAN

\section{Fisher's Model}

B. Aubrey Fisher is one of the more recognizable names of the literature and for good reason: they proposed a simple, yet efficient model of group development that is used frequently decades after its debut. There are still overlapping concepts and shared phases with other models presented, though it departs slightly from the structure Tuckman presented and has a higher degree of commonality with Tubb's Model.

\section{- Orientation}

The initial stage is once again about socializing rather than task achievement. Due to the lack of familiarity within the group's members, there is a primary tension that can only be deflated via interaction and norm definition. Fisher suggests that it is better to focus on interactivity rather than the usual performance-seeking behaviors.

\section{- Conflict}

The second stage is marked by a secondary tension, far more focused on the task rather than the social aspect. Conflict is the namesake of this stage and a degree of positivity is associated with it. Any discussion that turns into an operational debate is encouraged and it helps assess the efficiency of group processes as well as improve overall performance in later stages.

\section{- Emergence}

The third stage is the one in which the group starts reinforcing the structures and tasks debated during Conflict. It is now that changes begin to appear in attitudes and a degree of ideatic flexibility seeps into the mentality of group members.

\section{- Reinforcement}

The fourth stage is extremely brief compared to the norm and yet it is incredibly vital to the group. During this stage, a sense of calm and security spreads within the team as commitment halts any damaging conflict and decisions are easily accepted even by opposing team members. In Fisher's view, this stage is much more like a team that becomes something more than the sum of its parts, everyone feels accomplished, and interpersonal relations soar (Ellis and Fisher, 1994). 
GROUP DEVELOPMENT STAGES. A BRIEF COMPARATIVE ANALYSIS OF VARIOUS MODELS

\section{Jones' Model}

A model that details aspects less commonly discussed by its contemporaries, Jones' model has similarities with other models nonetheless, while being independent enough to have its own unique structure. There are several aspects unique to the model, including the final stage - team synergy, which make it stand out as an extra phase where excellence is considered part of the normal development a team should consider while experiencing its constituent processes.

- Immature Group

- The initial phase in the Jones Model is one represented by member orientation and an establishment of social interactions with a shift towards a socially acceptable pattern. Generally, the true or complete opinions of members are hidden under the initial contact's appearances.

- Fragmented Group

- During this phase conflicts between members have a halving effect on the team, with a divisionary character across opinion lines. Therefore, the group gains a fragmentation and cliques start to form where mutual idea sharing sessions are encouraged and dissent skyrockets.

- Sharing Group

During this phase, the team gains maturity and finds a middle ground where high cohesion can be asserted and leadership becomes flexible and attentive, as well as the group members.

- Effective Team

- During this phase, the team has consolidated its inner processes and is performing at a heightened rate. Here, like in most theories presented in the article, most of the team members find a balance and put a high degree of effort and commitment into the group's tasks.

- Team Synergy

- Team Synergy is where the group becomes more than the sum of its parts. Much like Esprit de Corps from other models, synergy aims for excellence and a melding between leader and team member. (Jones, 1975) 
SEBASTIAN VAIDA, DAN ȘERBAN

\section{Wheelan's Integrated Model}

Wheelan's Integrated Model was created by Susan Wheelan and built upon the work of Tuckman. Based upon the realization that Eastern cultures have embraced the idea that groups as entities can be more than the sum of their distinct parts and can themselves be distinct collectives, it attempts to shift the general view on group intelligence from focusing on "I" and more on "We".

As Briskin et al. (2009) note, the We perspective provides more engagement and integration, through the cumulative collective wisdom that a group entail. Studies in the field of neuroscience anchor this way of viewing groups as it has been shown that humans possess a "social brain", which responds and logs the interactions we have with each other (Goleman, 2011). The result is that group norms are essentially the pattern of interactions which have solidified into a group's collective psyche (Frederickson, 2003).

Wheelan (1996) validated her model using the Group Development Questionnaire. Her model remained consistent with the previous theories, particularly the chronology and staging aspects that are part of what we define as a group. Moreover, Wheelan's team discovered stage-specific patterns in the behavior of the teams. Most importantly, they underlined the dependency and trust-specific conversational patterns in the early stages of group development that preceded the work behaviors in the later stages. Adding to that, they propose that both the leaders and the members' way of conduct are equally important and that without a degree of group safety, no quality work can be achieved.

Due to the nature of Wheelan's work, we can see further similarities in the claims she makes compared to the work of Tuckman. As such, we see a level of energy being constantly applied into the interactions of the team members on a dependency and trust level regardless of their specific stages. Moreover, there is a distinct reliance on the leader in the early stages and a degree of developed group independence later. They advocate for a balance between ontask conversation and social-emotional issues, while repeating that there will always be unique development for each group (Wheelan, 2003).

The stages Wheelan (2003) proposes are as follows:

1. Dependency / Inclusion

2. Counter dependency / Conflict

3. Trust / Structure

4. Work / Productivity

The model involves a member-group-leader type of description for every stage and each stage follows a unique set of traits which summed up will describe the current state of the group. 
GROUP DEVELOPMENT STAGES. A BRIEF COMPARATIVE ANALYSIS OF VARIOUS MODELS

\section{Stage One: Dependency/Inclusion}

In this stage, we can talk about the initial contact of the group's members with each other under the pretense of creating a team. Here, members are tentative and polite, highly compliant and are afraid of being rejected. An appropriate response to most issues is conflict avoidance and high conformity. The entirety of the group assumes a consensus, roles are spread out according to external social factors and while there is a centralized communication pattern, there are no potent structural or organizational norms yet.

The leader is seen as a benevolent and competent member, who is expected to provide security and guidance. As such, they are rarely challenged and will be relied on to provide standards, mediate conversation, and provide safety to the group.

\section{Stage Two: Counter dependency / Conflict}

As the group progresses, the second stage is marked by an upturn in power towards the members. They will become increasingly participative into the task, thus identifying possible issues with the tasks and disagree about goals and tasks. Thus, they will challenge the leader and be encouraged by the situation to dissent, as the team becomes marked by conflict.

The group is decreasing in conformity, as cliques form and a subsequent intolerance for them is formed. While goals and clarifications are the main elements of this stage, subgroups remain a poignant problem. As such, when conflict resolution occurs, it naturally increases consensus and creates culture, while increasing overall trust and cohesion.

On a leadership level, the trend is not of blind resilience, but much more in favor of accepting changes and encouraging independence over fostering dependence. Therefore, the focus of the leader should be on encouraging a level of operational freedom.

\section{Stage Three: Trust/Structure}

On a member level, this stage is seen as a commitment spike point. Groups reaching this stage are dominantly pleased and satisfied and as such are working with elevated efficiency, but not peaking yet.

From the group's standpoint once can observe an increase in clarity and consensus. As this strengthens the bonds within the group, we can also mark the ascent of communication flexibility and task focused topics.

Leadership is even further de-escalated to an advisory role, with the guidance role taking a more pivotal status. Egalitarianism is the preferred approach to decision-making at this stage. 


\section{Stage Four: Work/Productivity}

This is perhaps the most coveted stage for most leaders. From a member point of view, it is the most clearly defined stage as it defined by goal clarity, agreement with goals, role sedimentation and voluntary conformity. All the above can only be held together by a heightened cooperativity within the group.

From the perspective of the entire group, it can be described as the stage where all the roles are assigned to those who fit them best. Communication is structured to match demands from tasks and is encouraging feedback.

Leadership-wise, we can see an improvement in delegating responsibility, and we can observe an increasing non-leadership model. While this occurs, one must make note of the fact that due to the advanced staging there is a degree of innate flexibility in the adopted style, and it will always strive to match the overall developmental level of the group.

Table 1. Models and stages synopsis.

\begin{tabular}{|c|c|c|c|c|c|}
\hline $\begin{array}{c}\text { Model } \\
\text { Name/ } \\
\text { Stage }\end{array}$ & Stage 1 & Stage 2 & Stage 3 & Stage 4 & $\begin{array}{l}\text { Stage } 5 \\
\text { (Bonus } \\
\text { Phase) }\end{array}$ \\
\hline $\begin{array}{l}\text { Bass \& } \\
\text { Ryterband }\end{array}$ & Acceptance & $\begin{array}{l}\text { Communication } \\
\text { and Decisions } \\
\text { Making }\end{array}$ & $\begin{array}{l}\text { Group } \\
\text { Solidarity }\end{array}$ & Group Control & - \\
\hline Tubb & Orientation & Conflicts & Consensus & Closure & - \\
\hline $\operatorname{Cog}$ & $\begin{array}{l}\text { The Polite } \\
\text { Phase }\end{array}$ & $\begin{array}{l}\text { "Why are we } \\
\text { here?" Phase }\end{array}$ & $\begin{array}{l}\text { The Power } \\
\text { Phase }\end{array}$ & $\begin{array}{l}\text { Cooperation } \\
\text { Phase }\end{array}$ & $\begin{array}{l}\text { The Esprit } \\
\text { de Corps } \\
\text { Phase }\end{array}$ \\
\hline Homan & $\begin{array}{l}\text { Needed states } \\
\text { and behaviors }\end{array}$ & $\begin{array}{l}\text { Emergent states } \\
\text { and behaviors }\end{array}$ & $\begin{array}{l}\text { Results of } \\
\text { collective } \\
\text { actions }\end{array}$ & - & - \\
\hline Woodcock & Infant Team & Exploratory Team & $\begin{array}{c}\text { Under } \\
\text { Consoli- } \\
\text { dation } \\
\text { Team }\end{array}$ & Mature Team & - \\
\hline Fisher & Orientation & Conflict & Emergence & Reinforcement & - \\
\hline Jones & $\begin{array}{c}\text { Immature } \\
\text { Group }\end{array}$ & $\begin{array}{l}\text { Fragmented } \\
\text { Group }\end{array}$ & $\begin{array}{l}\text { Sharing } \\
\text { Group }\end{array}$ & Effective Team & $\begin{array}{c}\text { Team } \\
\text { Synergy }\end{array}$ \\
\hline Tuckman & Forming & Storming & Norming & Performing & Adjourning \\
\hline Wheelan & $\begin{array}{l}\text { Dependency/ } \\
\text { Inclusion }\end{array}$ & $\begin{array}{c}\text { Counter } \\
\text { dependency / } \\
\text { Conflict }\end{array}$ & $\begin{array}{l}\text { Trust / } \\
\text { Structure }\end{array}$ & $\begin{array}{c}\text { Work / } \\
\text { Productivity }\end{array}$ & - \\
\hline
\end{tabular}


GROUP DEVELOPMENT STAGES. A BRIEF COMPARATIVE ANALYSIS OF VARIOUS MODELS

\section{Conclusions}

Group development is essential for every aspect of our personal and professional life. Understanding the theoretical models that describe this concept is as important as applying them in real life situations. In this article, we analyzed nine models of group development, to provide a better comprehension of the concept.

The first model we analyzed was the one developed by Bass and Ryterband (1979), which is a four-stage model (Acceptance, Communication and Decision Making, Group Solidarity, Group Control) that takes a different approach from the traditional linear stages, and only begins after the initial contacts have formed. The main plus of this model is that it focuses more on the fluidity of the team and on the interpersonal connections between team members than on the task-only processes. It also attempts and succeeds to explain a welldeveloped team as one that maximizes support and equity over raw performance scores. The second model in our analysis was Tubbs' (1978), which is a fourstage linear model (Orientation, Conflicts, Consensus and Closure) that takes a well-versed approach to group development. The stages focus on assessing the flexibility of leadership and team members, as well as keeping track of the detailed context of the team. Ranging from the organizational context to the technologies used and several system-related variables, Tubb's Model attempts to emphasize a need for intragroup flexibility and a need for closure and feedback, as opposed to measuring performance separate from the social aspects of the group. The third is called Cog's Ladder (Charrier, 1972) and is a five-stage linear model (The Polite Phase, "Why are we here?" Phase, The Power Phase, The Cooperation Phase and The Esprit de Corps Phase) inspired from a resultsoriented background. Thus, while it includes social-centric phases, it is far more concerned with the performance impact of various processes and phases that lead to the end-product. It is also one of the few models that includes an "excellence stage", concluding that if a group fully develops it can reach a high-performance stage where an idyllic closure can be reached. The fourth was developed by Homan (1950) and is a three-stage model (needed, states, and behaviors; emergent states and behaviors; results of collective actions) which takes a systemic approach to group development. Due to its pioneering status, it reinforces a reliance on contextual factors and internal and external systems, rather than a full overall view of the team development. It is a model heavily reliant on stability and clear developmental stages and tries to explain the evolution of teams via crossinfluences between contextual variables. The fifth is proposed by Woodcock (1979) and is a four-stage development model (Infant team, exploratory team, under consolidation team, mature team) which shares a high similarity with 
Tuckman's Model in its first iteration. It tries to observe the stages as a more social affair than other models and combines social and operational flexibility with performance as a way of assessing the current stage of a group. The sixth is Fisher's, a four-stage model (Orientation, Conflict, Emergence, Reinforcement), which uses a mixed approach that can be considered a middle ground between the Tubb and Tuckman models. It proposes a social dimension to all stages and a clear distinction between stages that are performance-centric and social-centric, as well as a brief reinforcement stage that surmises the culmination of efforts committed by groups. The seventh is Jones' model that uses five stages, including a bonus one that is centered on excellence (Immature Group, Fragmented Group, Sharing Group, Effective Team and Team Synergy). This model is heavily focused on interpersonal and social relations, declaring three stages focused on finding balance within the team and a latter one for measuring commitment and performance. The bonus stage is an exemplification of how a group can be more than the sum of its parts and in fact reach a level of informality when it excels. Tuckman's Model is the eight in our analysis and is one of the most widely known four/five stage model (Forming, Storming, Norming, Performing and the later added Adjourning). It involves clearly defined stages, which note both a performance and a social assessment of teams and a cyclical nature of teams, highly organic and close to organizational realities. Finally, the ninth model is Wheelan's, a four-stage model (Dependency/Inclusion, Counter dependency/Conflict, Trust/Structure, Work/Productivity) that combines leadership styles and a more traditional Tuckman-like structure to assess the cohesion and development of a group.

Although it would be interesting and useful to make a ranking of those models, they cannot be presented as such. Instead, depending on the several factors, one might choose to use one model over another.

If you and your team have already formed the initial contacts and if your leadership style is based on the relations and interpersonal connections between team members, and less on tasks, then a good approach is to use the model developed by Bass and Ryterband (1979). This is a more fluid model that allows you to work on diagnosing and developing concepts such as self and other acceptance, improving intra group communication, taking the right decisions for the group and overall improving the group solidarity. If you realize that your team needs constant feedback and closure, then Tubbs' model (1978) is recommended, as it emphasizes the intragroup flexibility, and monitoring the context of the team development. If you are in a high moving industry, where performance is a must, then you might want to have a look at Cog's Ladder (Charrier, 1972), which is the only one in our analysis that has an "excellence stage", for groups that manage to fully develop and reach high performance. If you want to work on a more classic perspective on group development, the two 
GROUP DEVELOPMENT STAGES. A BRIEF COMPARATIVE ANALYSIS OF VARIOUS MODELS

models proposed by Woodcock (1979) and Tuckman (1965) are best suited, as they follow a four, respectively five stages approach. This allows for a proper assessment of the stage that each group is or advances to. If you want to take the focus of your team and team members from individuality to group thinking and prioritizing, then Wheelan's approach is recommended, as it is a mix between Tuckman's traditional model and diverse leadership styles.

To conclude, no model is superior nor is it better than others are. Depending on the needs of your team, the experience and expertise you have as a leader, and the resources at hand (either financial or time bound), one model can be preferred over the other. What we ultimately recommend is to test these models in real situations and adapt them to the requirements of each specific team and situation.

\section{REFERENCES}

Bass, B. M., \& Ryterband, E. C. (1979). Organizational psychology. Allyn and Bacon.

Bonebright, D. A. (2010). 40 years of storming: A historical review of Tuckman's model of small group development. Human Resource Development International, 13(1), 111-120. doi:10.1080/13678861003589099

Briskin, A., Erickson, S., Ott, J. and Callanan, T. (2009), The Power of Collective Wisdom and the Trap of Collective Folly, Berrett-Koehler, San Francisco, CA.

Brown, L. N. (1991). Groups for growth and change. Longman.

Cassidy, K. 2007. Tuckman revisited: Proposing a new model of group development for practitioners. Journal of Experiential Education 29, no. 3: 413-7.

Charrier, G. O. (1972). Cog's ladder: A model of group growth. SAM Advanced Management Journal (00360805), 37(1), 30.

Curşeu Petru Lucian. (2007). Grupurile în organizaţii. Polirom.

Ellis, D. G., \& Fisher, B. A. (1994). Small group decision making: communication and the group process. McGraw-Hill.

Frederickson, B. L. (2003). The value of positive emotions. American Scientist, 91, $330-335$.

Goleman, D. (2011). Leadership: The power of emotional intelligence. More Than Sound LLC., 82-84

Gren, L., Torkar, R., \& Feldt, R. (2017). Group development and group maturity when building agile teams: A qualitative and quantitative investigation at eight large companies. Journal of Systems and Software, 124, 104-119. doi:10.1016/j.jss.2016.11.024

Homans, George C. (1950) The Human Group. New York: Harcourt, Brace and Company.

Ito, J.K., Brotheridge, C.M., Do teams grow up one stage at a time? Exploring the complexity of group development models, Team Performance Management, Vol. 14, No. 5/6, 2008, pp. 214-232 
Jones, A. (2019). The Tuckman'S Model Implementation, Effect, And Analysis \& The New Development of Jones Lsi Model On a Small Group. Journal of Management, 6(4). doi:10.34218/jom.6.4.2019.005

Jones, J. E., \& Pfeiffer, J. W. (1975). The 1975 annual handbook for group facilitators. University Associates.

Natvig, D., \& Stark, N. L. (2016). A Project Team Analysis Using Tuckman's Model of Small-Group Development. Journal of Nursing Education, 55(12), 675-681. doi:10.3928/01484834-20161114-03

Pugalis, L., \& Bentley, G. (2013). Storming or performing? Local Enterprise Partnerships two years on. Local Economy: The Journal of the Local Economy Policy Unit, 28(78), 863-874. doi:10.1177/0269094213503066

Seck, M. M., \& Helton, L. (2014). Faculty Development of a Joint MSW Program Utilizing Tuckman's Model of Stages of Group Development. Social Work with Groups, 37(2), 158-168. doi:10.1080/01609513.2013.828908

Sundstrom, E., De Meuse, K. P., \& Futrell, D. (1990). Work teams: Applications and effectiveness. American Psychologist, 45(2), 120-133. https://doi.org/10.1037/0003-066X.45.2.120

Tubbs, S. L. (1978). A systems approach to small group interaction. New York: Random House.

Tuckman, B. W. (1965). Developmental sequence in small groups. Psychological Bulletin, 63(6), 384-399. doi:10.1037/h0022100

Tuckman, B. W., \& Jensen, M. A. (1977). Stages of Small-Group Development Revisited. Group \& Organization Studies, 2(4), 419-427. doi:10.1177/105960117700200404

Wheelan, S. (2003). An initial exploration of the internal dynamics of leadership teams. Consulting Psychology Journal, 55 (3), 179-188.

Wheelan, S. A., Davidson, B., \& Tilin, F. (2003). Group Development Across Time. Small Group Research, 34(2), 223-245. doi:10.1177/1046496403251608

Wheelan, S. A., \& Hochberger, J. M. (1996). Validation studies of the group development questionnaire. Small group research, 27(1), 143-170.

Woodcock, M., (1979), Team development manual, Gower Publishing, London.

Zhen, J. (2017). Application of Tuckman's Model in the Community Folk Team Management in Community Education. Proceedings of the 3rd Annual International Conference on Social Science and Contemporary Humanity Development. doi:10.2991/sschd-17.2017.34

Zoltan, R., \& Vancea, R. (2016). Work group development models-the evolution from simple group to effective team. Ecoforum Journal, 5(1). 